УДК 620.197 .3

DOI: 10.17072/2223-1838-2021-4-254-262

А. С. Калинина, И. С. Полковников, А. Б. Шеин

Пермский государственный национальный исследовательский университет, Пермь, Россия

\author{
ИССЛЕДОВАНИЕ РЯДА КОМПОЗИЦИЙ МАРКИ «СОЛИНГ» В КАЧЕСТВЕ \\ ИНГИБИТОРОВ КОРРОЗИИ МАЛОУГЛЕРОДИСТОЙ СТАЛИ В КИСЛЫХ СРЕДАХ
}

Методами поляризаџионных и гравиметрических измерений изучено защитное действие композииий серии "Солинг» различных марок на малоуглеродистую сталь Стз в растворах 5- $и$ 15\%-ной $\mathrm{HCl}$ и 5\%-ной $\mathrm{H}_{2} \mathrm{SO}_{4}$. Рассчитаны защитный эффект, коэффициент торможения коррозионного прочесса, определены наклоны Тафелевских участков поляризачионных кривых в катодной и анодной области. Определено влияние ингибиторов на кинетику парииальных электрохимических реакиий. Произведена оценка состояния поверхности образиов при помощи микрофотографий. Показана высокая эффективность ингибиторов в кисльх средах.

Ключевые слова: коррозия; ингибитор; защитное действие; серная кислота; соляная кислота

Поступила в редакцฺию 27.09.2021; принята к публикации 25.10.2021

\author{
A. S. Kalinina, I. S. Polkovnikov, A. B. Shein \\ Perm State University, Perm, Russia

\section{INVESTIGATION OF SOME COMPOSITIONS OF THE «SOLING» SERIES AS CORROSION INHIBITORS FOR LOW-CARBON STEEL IN ACIDIC MEDIA}

The inhibiting effect of some compositions of «Soling》 series on low-carbon steel St 3 in solutions of $5 \%$ and $15 \% \mathrm{HCl}$ and $5 \% \mathrm{H}_{2} \mathrm{SO}_{4}$ has been studied by the methods of polarization and gravimetric measurements. The protective action and the coefficient of inhibition of the corrosion process are calculated, the slopes of the Tafel sections in the cathode and anode regions of the polarization curves have been calculated. The influence of inhibitors on the kinetics of partial electrochemical reactions has been determined. The state of the surface of the samples has been estimated using micrographs. The high efficiency of inhibitors in acidic media has been shown.

Keywords: corrosion, inhibitor, protective effect, sulfuric acid, hydrochloric acid

Received 27.09.2021; accepted 25.10.2021

() Калинина А.С., Полковников И.С., Шеин А.Б., 2021 
В современном мире нас окружает большое число конструкционных материалов, включая металлы и их сплавы. Области их применения обширны, в качестве одного из основных потребителей металлических конструкций выступает нефтегазовая промышленность. Чтобы обеспечить непрерывную добычу и транспортировку нефти и газа, необходимо тщательно подбирать материалы и стремиться к увеличению срока их эксплуатации [1-6].

Одной из важнейших проблем, с которыми сталкивается современное производство, является коррозия [4-7]. Почти любая водная среда может способствовать коррозии, которая происходит в многочисленных комплексных условиях в системах добычи, переработки и трубопроводами добычи нефти и газа. Для интенсификации нефтедобычи в скважины добавляют соляную кислоту, а для удаления окалины с металлических изделий - серную кислоту, в результате нефтегазовое оборудование значительное время находится в контакте с агрессивной средой $[6,7]$. С течением времени оборудование стареет или разрушается вследствие коррозии, что приводит его в негодность. Это влечет за собой не только экономические потери, но и способствует загрязнению окружающей среды и создает угрозу для здоровья человека.

Защита металлов от коррозии при помощи ингибиторов является одним из наиболее эффективных, экономичных способов предотвращения коррозионных потерь [2, 8-10]. Уже при малых концентрациях ингибиторов существенно снижаются коррозионные потери. Для решения сложных задач, связанных с коррозионным разрушением металлических изделий и конструкций, необходимо создание и изучение новых более совершенных ингибиторов коррозии полифункционального действия, которые в той или иной степени будут удовлетворять всем поставленным требованиям.

Целью данной работы является исследование ряда композиций серии «Солинг» в качестве ингибиторов коррозии малоуглеродистой стали (Ст3) в кислой среде методами гравиметрических испытаний и постояннотоковых измерений, а также определение механизма действия ингибиторов.

\section{Объекты и методы исследования}

Материалом для исследования служили образцы, изготовленные из малоуглеродистой стали Ст3 состава, \% (мас.): $\mathrm{Fe}-98,36$; C - 0,2; $\mathrm{Mn}-0,5 ; \mathrm{Si}-0,15 ; \mathrm{P}-0,04 ; \mathrm{S}-0,05 ; \mathrm{Cr}-0,3$; $\mathrm{Ni}-0,2 ; \mathrm{Cu}-0,2$. Эксперименты выполнялись при температуре $20^{\circ} \mathrm{C}$ в условиях естественной аэрации в растворах 5-, 15\%-нойНCl, 5\%ной $\mathrm{H}_{2} \mathrm{SO}_{4}$, приготовленных на основе дистиллированной воды и кислот $\mathrm{HCl}, \mathrm{H}_{2} \mathrm{SO}_{4}$ марки «Х.ч.». В качестве ингибиторов использовались композиции серии «Солинг» под марками Д и ЛУ (основа - четвертичное аммонийное основание с разным содержанием ПАВ), Т и 21 (основа - высокомолекулярное азотсодержащее ПАВ с различными добавками). Концентрация ингибиторов $0,05-0,2$ г/л.

Скорость коррозии стали оценивали гравиметрическим методом согласно общепринятой методике [11]. Для этих испытаний использовали пластинки прямоугольной формы из стали Ст3 размером 25х20х2 мм. Рабочая площадь поверхности составляла $\approx 1200 \mathrm{Mм}^{2}$. Исследуемые образцы перед исследованием зачищали наждачной бумагой, обезжиривали этиловым спиртом или ацетоном, высушивали и взвешивали на аналитических весах с точно- 
стью до 0,0001 г. Далее металлические пластинки погружали в раствор кислоты на 24 часа. По окончании эксперимента образцы извлекали, промывали дистиллированной водой, просушивали фильтровальной бумагой, удаля- ли продукты коррозии мягким ластиком, обезжиривали и вновь взвешивали.

Состояние поверхности образцов после эксперимента оценивали при помощи металлографического микроскопа «Olympus BX51».

Таблица 1

Защитное действие $(Z)$ и ингибиторный эффект $(\gamma)$ композиций «Солинг» на Ст3 в кислых средах

\begin{tabular}{|c|c|c|c|c|c|c|c|}
\hline \multirow{2}{*}{ Ингибитор } & \multirow{2}{*}{$\mathcal{C}_{\text {инг }}$, глл } & \multicolumn{5}{|c|}{ Основные показатели коррозии } \\
\cline { 3 - 8 } & & \multicolumn{2}{|c|}{$5 \% \mathrm{HCl}$} & \multicolumn{2}{|c|}{$15 \% \mathrm{HCl}$} & \multicolumn{2}{c|}{$5 \% \mathrm{H}_{2} \mathrm{SO}_{4}$} \\
\cline { 3 - 8 } & & $Z, \%$ & $\gamma$ & $Z, \%$ & $\gamma$ & $Z, \%$ & $\gamma$ \\
\hline \multirow{3}{*}{$\mathrm{T}$} & 0,05 & 83 & 5,84 & 95 & 23,11 & - & - \\
& 0,1 & 93 & 13,93 & 97 & 31,50 & 85 & 6,49 \\
21 & 0,2 & 89 & 9,03 & 97 & 31,08 & 81 & 5,22 \\
\hline \multirow{3}{*}{2} & 0,05 & 2 & 1,02 & 75 & 3,95 & - & - \\
& 0,1 & 4 & 1,04 & 87 & 7,86 & 42 & 1,73 \\
& 0,2 & 91 & 10,52 & 95 & 19,58 & 74 & 3,82 \\
\hline \multirow{3}{*}{ ЛУ } & 0,05 & 82 & 5,50 & 87 & 7,70 & - & - \\
& 0,1 & 87 & 7,98 & 91 & 10,61 & -84 & 0,54 \\
& 0,2 & 87 & 7,84 & 94 & 16,93 & 42 & 1,72 \\
\hline & 0,05 & 79 & 4,72 & 90 & 9,80 & - & - \\
& 0,1 & 88 & 8,35 & 94 & 16,56 & 84 & 6,35 \\
& 0,2 & 87 & 7,70 & 97 & 32,70 & 88 & 8,37 \\
\hline
\end{tabular}

Для определения механизма действия ингибиторов коррозии стали Ст3 в растворах 5- и $15 \%$-нойНСl использовали потенциодинамический метод снятия поляризационных кривых. Снятие поляризационных кривых производилось в потенциодинамическом режиме из катодной области в анодную со скоростью развертки потенциала $0,5 \mathrm{mB} / \mathrm{c}$.

Для снятия поляризационных кривых использовали электрохимический измерительный комплекс Solartron 1280C, состоящий из анализатора импеданса SI 1255 и потенциостата SI 1287 в трехэлектродной ячейке ЯСЭ-2 с раздельными катодным и анодным пространствами. Электрохимические исследования проводились на стальном электроде с площадью поверхности $1 \mathrm{~cm}^{2}$. Электродом сравнения служил насыщенный хлорсеребряный электрод, вспомогательным - платиновый элек- трод. Все значения потенциала приведены относительно стандартного водородного электрода.При измерениях и обработке данных использовали программы CorrWare2, CorrView2 (Schribner Associates, Inc.).

\section{Результаты и обсуждение}

Результаты гравиметрических испытаний Ст3 в растворах 5- и $15 \%$-ной $\mathrm{HCl}$ и $5 \%$-ной $\mathrm{H}_{2} \mathrm{SO}_{4}$ представлены в табл. 1. Согласно результатам гравиметрических испытаний, представленных в табл.1, исследованные вещества демонстрируют различный защитный эффект. Согласно классификации эффективности защиты ингибиторов [12] в растворах соляной кислоты композиции серии «Солинг» обладают отличным защитным эффектом, а в растворах серной кислоты - средним. В растворах соляной кислоты защитное действие имеет более высокие значения (79-97 \%), чем в рас- 
творе серной кислоты (42-88 \%). Максимальное защитное действие ингибиторов серии «Солинг» наблюдается в $15 \%$-ном растворе $\mathrm{HCl}$ при добавлении марки ЛУ и Т (97 \%), при этом наблюдается торможение скорости коррозии примерно в 30 раз. Действие ингибиторов в растворе серной кислоты имеет неоднозначный характер. Значения защитного действия $\mathrm{Z}$ находятся ниже 90 \%, а при добавлении ингибитора марки Д наблюдается обратный эффект - ускорение растворения стального образца.

Зависимость ингибиторного эффекта от концентрации ингибиторов в логарифмических координатах для 5\%-ной $\mathrm{HCl}$ представлена на рис. 1.

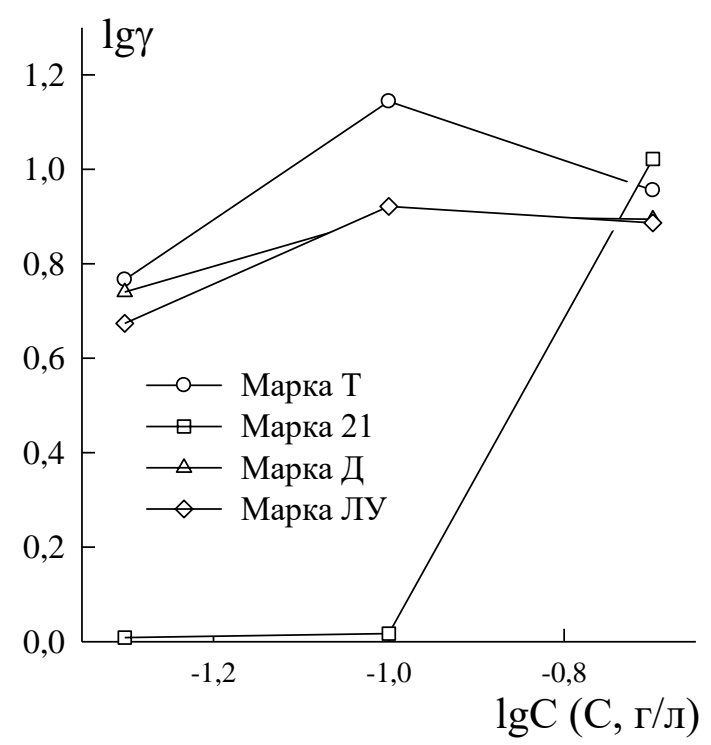

Рис.1. Зависимость логарифма ингибиторного эффекта от логарифма концентрации в 5\%-ной $\mathrm{HCl}$ для ингибиторов «Солинг»

C ростом концентрации ингибитора замедление скорости коррозии проходит через максимум, максимальное торможение наблюдается при концентрации ингибиторов 0,1 г/л (марка Т, марка Д, марка ЛУ). В растворе
$15 \%$-ной $\mathrm{HCl}$ отсутствует выраженный максимум, и значение коэффициента торможения растет с ростом концентрации ингибитора.

Различное поведение ингибиторов серии «Солинг» в кислых средах может быть обусловлено сложным составом композиции. В растворах серной и соляной кислот поверхность оказывается заряжена по-разному [13]. В результате ингибиторы имеют разную степень адгезии к поверхности стали. Ингибиторный эффект четвертичных аммонийных оснований во многом основан на экранировании поверхности металла, вероятно, из-за этого защитный эффект недостаточен в растворе серной кислоты [14].

Дополнительная информация о защитном действии ингибиторов была получена при помощи микрофотографий поверхности, представленных на рис. 2.

На микрофотографиях образцов Ст3 можно увидеть низкую эффективность ингибиторов в растворе серной кислоты (рис. 2 а, б): поверхность сильно растравливается, увеличивается количество дефектов. Добавление ингибитора в систему слабо сказывается на виде стальных образцов.

Обратная картина наблюдается в растворах соляной кислоты (рис. 2 в, г, д, е). Поверхность образца, находившегося в растворе с добавлением ингибиторов серии «Солинг», растравлена меньше, она сохраняет следы зачистки и уменьшается число дефектов. С увеличением концентрации $\mathrm{HCl}$ до 15\% состояние поверхности в присутствии ингибиторов также близко к исходной поверхности образца, что подтверждает результаты гравиметрических испытаний. 


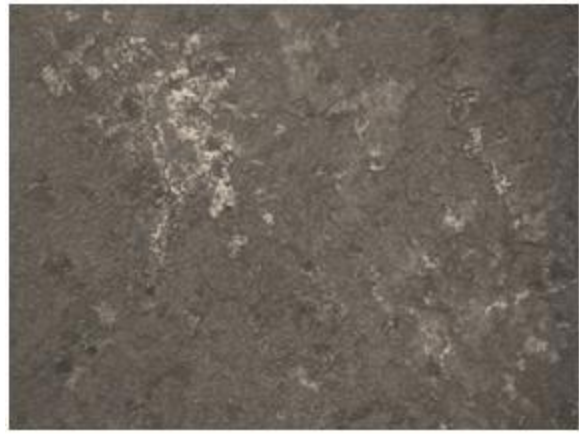

a

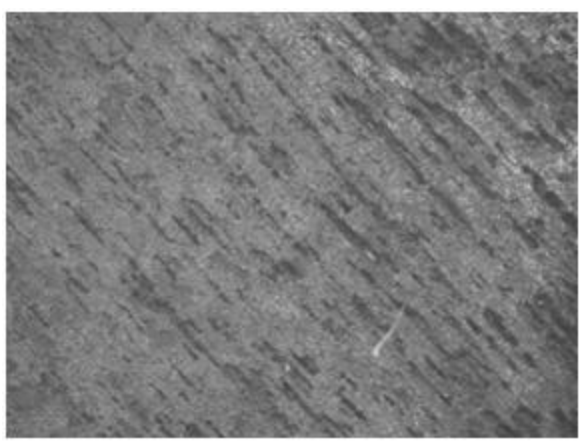

B

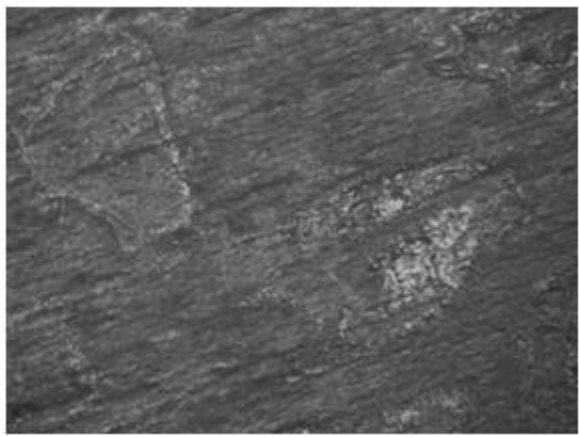

д

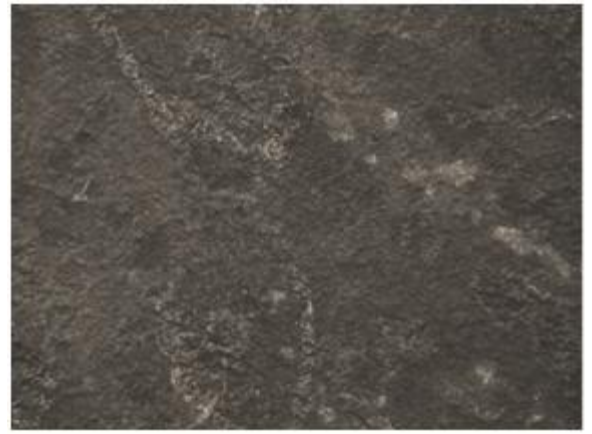

6

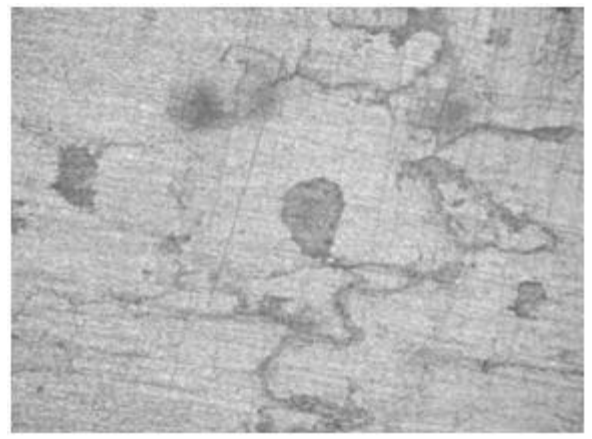

$\Gamma$

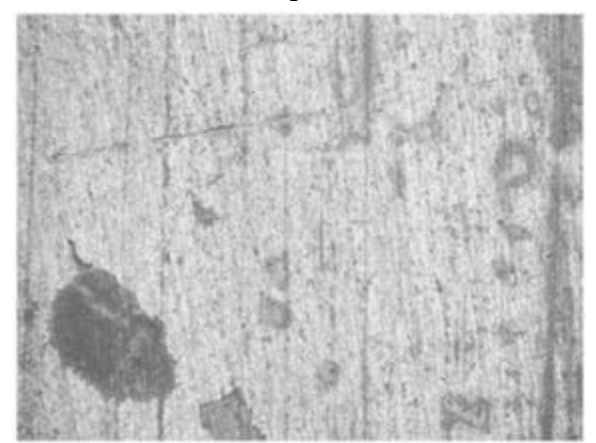

e

Рис. 2. Микрофотографии поверхности образцов Ст3 (×100) после 24-часовой выдержки в растворах

$5 \%$-ной $\mathrm{H}_{2} \mathrm{SO}_{4}(\mathrm{a}$, б), 5\%-ной $\mathrm{HCl}(\mathrm{в}$, г) и 15\%-нойНCl (д, е): без добавления ингибитора (а, в, д) и с добавлением 0,1 г/л ингибитора марки Д (б, г, е)

Для определения механизма действия ингибиторов были получены поляризационные кривые на Ст3 в растворах 5- и 15\%-ной $\mathrm{HCl}$, представленные на рис. 3 и 4.

Скорость любого электрохимического процесса зависит от скорости двух сопряженных реакций на поверхности электрода [15], коррозионный процесс не является исключением. В качестве анодной реакции выступает переход ионов металла из решетки в раствор, в качестве катодной - ассимиляция электронов, которые освобождаются в ходе анодной реак- ции одним из деполяризаторов. Добавление ингибитора может замедлять как один из парциальных процессов, так и оба [16]. Полученные поляризационные кривые подтверждают ингибиторный эффект композиций марки «Солинг» (рис. 3, 4). Результаты постояннотоковых измерений говорят о смешанном характере ингибирования, происходит уменьшение плотности тока катодной и анодной ветвей. Количественные характеристики поляризационных кривых представлены в табл. 2,3. В растворе 5\%-ной $\mathrm{HCl}$ значения защитного дей- 
ствия $Z_{\text {эл/x }}$ меньше (в сравнении с показаниями гравиметрических испытаний). Полученные результаты можно объяснить разным временем нахождения образцов в растворе [17]: в

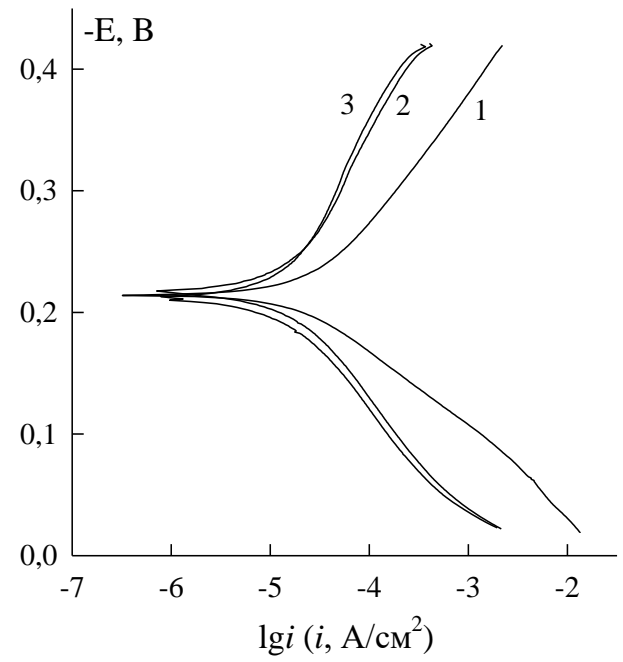

Рис. 3. Поляризационные кривые стали Ст3 в растворе 5\%-ной $\mathrm{HCl}$ при комнатной температуре:

1 -без ингибитора; 2 - с добавлением 0,1 г/л ингибитора марки Т; 3 - с добавлением 0,2г/л ингибитора марки Т ходе гравиметрии образцы находились в агрессивной среде в течение 24 часов, а в ходе электрохимических испытаний - в течение одного часа.

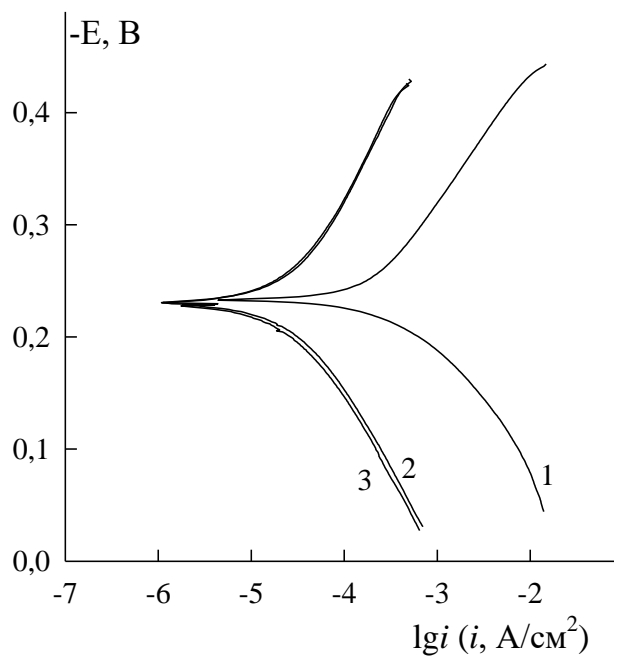

Рис. 4. Поляризационные кривые стали Ст3 в растворе $15 \%$-ной $\mathrm{HCl}$ при комнатной температуре:

1 -без ингибитора; 2 - с добавлением 0,1 г/л ингибитора марки Т; 3 - с добавлением 0,2г/л ингибитора марки Т

Таблица 2

Коррозионно-электрохимические характеристики Ст3 в 5\%-ном растворе НСІ

с добавлением 0,1-0,2 г/л ингибиторов серии «Солинг»

\begin{tabular}{|c|c|c|c|c|c|c|}
\hline Ингибитор & $\begin{array}{c}C, \\
\text { г/л }\end{array}$ & $\begin{array}{c}b_{a}, \\
\mathrm{MB}\end{array}$ & $\begin{array}{c}b_{k}, \\
\mathrm{MB}\end{array}$ & $\begin{array}{c}i_{\text {ко }}{ }^{*} 10^{-4}, \\
\mathrm{~A} / \mathrm{M}^{2}\end{array}$ & $\begin{array}{c}-E_{\text {кор }}, \\
\mathrm{B}\end{array}$ & $\begin{array}{c}Z_{\text {эл/x }}, \\
\%\end{array}$ \\
\hline $5 \% \mathrm{HCl}$ & - & 67 & 88 & 0,23 & 0,214 & - \\
21 & 0,1 & 103 & 115 & 0,10 & 0,245 & 70 \\
21 & 0,2 & 86 & 105 & 0,11 & 0,238 & 67 \\
Д & 0,1 & 137 & 153 & 0,19 & 0,230 & 42 \\
Д & 0,2 & 101 & 147 & 0,18 & 0,237 & 45 \\
Т & 0,1 & 83 & 92 & 0,11 & 0,220 & 67 \\
Т & 0,2 & 111 & 192 & 0,18 & 0,215 & 45 \\
ЛУ & 0,1 & 104 & 153 & 0,14 & 0,232 & 58 \\
ЛУ & 0,2 & 136 & 199 & 0,14 & 0,243 & 58 \\
\hline
\end{tabular}

Независимо от концентрации кислоты при добавлении ингибиторов в раствор происходит уменьшение тока коррозии и увеличение Тафелевских наклонов как катодной, так и анодной ветви поляризационной кривой. Увеличение наклона сигнализирует также об изменении состояния поверхности образца Ст3. Ве- роятно, ингибиторы блокируют поверхность стали, в результате чего вызывают перенапряжение катодного и анодного процессов [15] и замедление коррозионного процесса.

\section{Заключение}

Композиции серии «Солинг» марок Т, 21, Д, ЛУ показали высокую степень защиты ста- 
ли марки Ст3 в растворах 5- и $15 \%$-ной $\mathrm{HCl}$ и среднюю степень защиты в растворе 5\%-ной $\mathrm{H}_{2} \mathrm{SO}_{4}$. Максимальное защитное действие в растворе 5 \%-ной $\mathrm{HCl}$ наблюдался для ингибиторов марки Т и 21 (93\% и 91 \% соответственно), а в $15 \%$-ной $\mathrm{HCl}$ - для марки Т и ЛУ (97 \% в обоих случаях). Оптимальной концентрацией является 0,1 г/л. Результаты электро- химических исследований показали, что исследованные ингибиторы относятся к классу ингибиторов смешанного типа, так как тормозят обе парциальные электродные реакции.

\section{Конфликт интересов}

Авторы заявляют об отсутствии конфликта интересов.

Коррозионно-электрохимические характеристики Ст3 в $15 \%$-ном растворе $\mathrm{HCl}$

с добавлением 0,1-0,2 г/л ингибиторов серии «Солинг»

\begin{tabular}{|c|c|c|c|c|c|c|}
\hline Ингибитор & $\begin{array}{c}C, \\
2 / \Omega\end{array}$ & $\begin{array}{c}b_{a}, \\
\mathrm{MB}\end{array}$ & $\begin{array}{c}b_{k}, \\
\mathrm{MB}\end{array}$ & $\begin{array}{c}i_{\text {кор }}{ }^{*} 10^{-4}, \\
\mathrm{~A} / \mathrm{m}^{2}\end{array}$ & $\begin{array}{c}-E_{\text {кор }}, \\
\mathrm{B}\end{array}$ & $\begin{array}{c}Z_{\text {эл/x }}, \\
\%\end{array}$ \\
\hline $15 \% \mathrm{HCl}$ & - & 64 & 112 & 1,80 & 0,236 & - \\
21 & 0,1 & 111 & 113 & 0,30 & 0,225 & 83 \\
21 & 0,2 & 87 & 83 & 0,12 & 0,236 & 93 \\
Д & 0,1 & 84 & 115 & 0,14 & 0,222 & 92 \\
Д & 0,2 & 98 & 106 & 0,14 & 0,222 & 92 \\
Т & 0,1 & 81 & 109 & 0,18 & 0,217 & 90 \\
Т & 0,2 & 98 & 108 & 0,18 & 0,221 & 90 \\
ЛУ & 0,1 & 111 & 103 & 0,17 & 0,236 & 91 \\
ЛУ & 0,2 & 103 & 109 & 0,16 & 0,230 & 91 \\
\hline
\end{tabular}

\section{Список литературы}

1. Roberge P.R. Handbook of corrosion engineering. New York: McGraw-Hill, 2000. 1140 p.

2. Steel Designer's Manual / Ed. by Deacon D., Hudson R. London: Wiley-Blackwell, 2012. $1371 \mathrm{p}$.

3. Мальщева Г.Н. Коррозия и защита оборудования от коррозии. Пенза: Изд-во Пенз. гос. ун-та, 2001. 187 с.

4. Каи Н.Г., Стариков В.П., Парфенова С.Н. Химическое сопротивление материалов и защита оборудования нефтегазопереработки от коррозии. М.: Машиностроение, 2011. $436 \mathrm{c}$.

5. Коррозия и защита от коррозии / под ред. И.В. Семеновой. М.: ФИЗМАТЛИТ, 2002. $336 \mathrm{c}$.
6. Токунов В.И., Саушин А.3. Технологические жидкости и составы для повышения продуктивности нефтяных и газовых скважин. М.: Недра, 2004. 711 с.

7. Рябов В.Д. Химия нефти и газа.М.: ИД «ФОРУМ», 2009. $336 \mathrm{c}$.

8. Решетников С.М. Ингибиторы кислотной коррозии металлов. Л.: Химия, 1986. 144 с.

9. Вагапов Р. К., Бизяева В. С., Кичигин В. И. Подбор ингибиторов коррозии для защиты нефтепромыслового оборудования // Коррозия: материалы, защита. 2006. Т. 4. С. 24-28.

10. Palanisamy G. Corrosion inhibitors. London: Intechopen, 2019. $192 \mathrm{p}$.

11.ГОСТ 9.505-86. Единая система защиты от коррозии и старения. Ингибиторы кислотной коррозии. Методы испытаний защит- 
ной способности при кислотном травлении металлов. М.: Государственный комитет СССР по стандартам, 1986. 16 с.

12. Вигдорович В. И., Стррельникова К.О. Критерии оценки защитной эффективности ингибиторов коррозии // Конденсированные среды и межфазные границы. 2011. Т. 13, № 1. C. 24-28.

13. Антропов Л.И. Теоретическая электрохимия. М.: Высшая школа, 1984. 519 с.

14. Угрюмов О.В., Ивщин О.В., Фахретдинов П. С. Ингибиторы коррозии металлов ряда $\mathrm{N}$-[изононилфеноксиполи (этиленокси)карбонилметил] аммоний хлоридов. I. Ингибирование коррозии стали в солянокислых водных средах // Защита металлов. 2001. T. 37, № 4. C. 380-385.

15. Розенфельд И.Л. Ингибиторы коррозии металлов. М.: Химия, 1977.350 с.

16. Кузнецов М.В., Новоселов В.Ф. Противокоррозионная защита трубопроводов и резервуаров. М.: Недра, 1992. 238 с.

17. Меньшиков И.А., Шеин А.Б. Защита от коррозии малоуглеродистой стали в кислых средах ингибиторами серии СОЛИНГ// Химия и химическая технология. 2016. Т. 59, № 2. С. $70-73$.

\section{References}

1. Roberge, P.R. (2000) Handbook of corrosion engineering, McGraw-Hill, New York, USA.

2. Deacon, D. and Hudson, R. (ed.) (2012) Steel Designer's Manual, Wiley-Blackwell, London, UK.

3. Mal'tseva, G.N. (2001) Korroziya i zashchita oborudovaniya ot korrozii [Corrosion and equipment corrosion protection], Penza State University, Penza. (in Russ.).
4. Kats, N.G., Starikov, V.P. and Parfenova, S.N. (2011) Khimicheskoe soprotivlenie materialov $i$ zashchita oborudovaniya neftegazopererabotki ot korrozii [Chemical resistance of materials and protection of oil and gas processing equipment from corrosion], Mashinostroenie, Moskow. (in Russ.).

5. Semenova, I.V. (ed.) (2002) Korroziya i zashchita ot korrozii [Corrosion and corrosion protection], Fizmatlit, Moscow (in Russ.).

6. Tokunov, V.I. and Saushin, A.Z. (2004) Tekhnologicheskie zhidkosti $i$ sostavy dlya povysheniya produktivnosti neftyanykhigazovykh skvazhin [Technological fluids and compositions for increasing the productivity of oil and gas wells], Nedra, Moscow. (in Russian).

7. Ryabov, V.D. (2009) Khimiya nefti $i$ gaza. [Chemistry of oil and gas], Forum, Moscow. (in Russ.).

8.Reshetnikov, S.M. (1986) Ingibitory kislotnoj korrozii metallov [Inhibitors of acid corrosion of metals], Khimiya, Leningrad. (in Russ.).

9. Vagapov, R.K., Bizyaeva, V.S., Kichigin, V.I. (2006), "Selection of corrosion inhibitors for protecting the oil field equipment", Protection of Metals, vol. 42, no. 4, pp. 24-28. (in Russ.)

10. Palanisamy, G. (2019) Corrosion inhibitors, Intechopen, London, UK.

11. USSR State Committee for Standards (1986), GOST 9.505-86. Unified system of protection against corrosion and aging.Acid corrosion inhibitors.Methods for testing the protective ability during acid etching of metals, Moscow, USSR. (in Russ.).

12. Vigdorovich, V.I. and Strel'nikova, K.O. (2011), "Criteria to assess the protective effectiveness of corrosion inhibitors", Condensed 
Matter and Interphases, vol. 13, no.1, pp. 24-28. (in Russ.).

13. Antropov, L.I. (1984) Teoreticheskajay elektrohimija [Theoretical electrochemistry], Vyshaya Shkola, Moscow. (in Russ.).

14. Ugryumov, O.V., Fakhretdinov, P.S., Romanov, G.V., Ivshin, Ya.V. and Kaidrikov, R.A. (2001), "N-[Isononylphenoxypoly (Ethyleneoxy) Carbonylmethyl]Ammonium Chlorides As Inhibitors Of Metal Corrosion. I. Inhibition Of Steel Corrosion In Aqueous Hydrochloric Media", Protection of Metals, vol. 37, no. 4, pp. 380-385. (in Russ.).

\section{Об авторах}

Анна Сергеевна Калинина, студент, кафедра физической химии Пермский государственный национальный исследовательский университет 614990, г. Пермь, ул. Букирева, 15. https://orcid.org/0000-0002-4049-8646 anykakalinina@yandex.ru

Игорь Сергеевич Полковников, аспирант, кафедра физической химии Пермский государственный национальный исследовательский университет 614990, г. Пермь, ул. Букирева, 15. https://orcid.org/0000-0003-4381-6467 igorsergeevichp@gmail.com

Анатолий Борисович Шеин, доктор химических наук, профессор кафедры физической химии Пермский государственный национальный исследовательский университет 614990, г. Пермь, ул. Букирева, 15. ashein@psu.ru https://orcid.org/0000-0002-2102-0436
15. Rozenfel'd, I.L. (1977) Ingibitory korrozii metallov [Inhibitors of metal corrosion], Khimiya, Moscow (in Russian).

16. Kuznecov, M.V. and Novoselov, V. F. (1992) Protivokorrozionnaja zashhita truboprovodov $i$ rezervuarov [Corrosion protection of pipelines and reservoirs], Nedra, Moscow. (in Russ.).

17. Menshikov, I.A. and Shein, A.B. (2016), "Corrosion protection of low-carbon steel in acidic media by inhibitors of soling series", Russian Journal of Chemistry and Chemical Technology, vol. 59, no. 2, pp. 70-73. (in Russ.).

\author{
About the authors \\ Anna S. Kalinina, \\ student, Department of Physical Chemistry \\ Perm State University \\ 15, Bukireva st., Perm, Russia, 614990 \\ https://orcid.org/0000-0002-4049-8646 \\ anykakalinina@yandex.ru
}

Igor S. Polkovnikov,

Postgraduate student, Department of Physical Chemistry, Perm State University 15, Bukireva st., Perm, Russia, 614990 https://orcid.org/0000-0003-4381-6467 igorsergeevichp@gmail.com

Anatoly B. Shein, Doctor of Chemistry Sciences, Professor, Department of Physical Chemistry Perm State University 15, Bukireva st., Perm, Russia, 614990 ashein@psu.ru https://orcid.org/0000-0002-2102-0436

\section{Информация для цитирования:}

Калинина А.С., Полковников И.С., Шеин А.Б. Исследование ряда композиций марки «Солинг» в качестве ингибиторов коррозии малоуглеродистой стали в кислых средах// Вестник Пермского университета. Серия «Химия». 2021. Т. 11, вып. 4. С. 254-262. DOI: 10.17072/2223-1838-2021-4-254-262.

Kalinina A.S., Polkovnikov I.S., Shein A.B. Investigation of some compositions of the soling series as corrosion inhibitors for low-carbon steel in acidic media, Bulletin of Perm University. Chemistry, 2021, vol. 11, no. 4, pp. 254-262. (In Russ.). DOI: 10.17072/2223-1838-2021-4-254-262. 